\title{
“PSICOLOGIA EM ESTUDO”: CONHECENDO O PERIODICO
}

Marilda Gonçalves Dias Facci ${ }^{1}$; Aline Sanches ${ }^{2}$; Adriana de Fatima Franco ${ }^{3}$; Alvaro Marcel Palomo Alves ${ }^{4}$; Daniele de Andrade Ferrazza ${ }^{5}$; Glaucia Valéria Pinheiro Brida ${ }^{6}$; Hilusca Alves Leite ${ }^{7}$; Lucas Martins Soldera ${ }^{8}$; Maria Therezinha Loddi Liboni ${ }^{9}$; Murilo Moscheta $^{10}$; Zaira de Fátima Rezende Gonzalez Leal ${ }^{11}$

\section{Como citar:}

FACCI, M. G. D.; SANCHES, A.;FRANCO, A. F.; ALVES, A. M. P.; FERRAZZA, D. A., BRIDA, G. V. P.; LEITE, H. A.; SOLDERA, L. M.; LIBONE, M. T. L.; MOSCHETA, M.; LEAL, Z. F. R. G. "Psicologia em estudo": conhecendo o periódico. In: ABEC MEETING, 1, 2017, Curitiba. Anais... Curitiba: Associação Brasileira de Editores Científicos, 2017. p. 1-5. http://dx.doi.org/10.21452/abecmeeting.2017.001

Resumo: O objetivo deste pôster é apresentar algumas informações sobre a revista Psicologia em Estudo. O periódico tem como missão publicar textos originais sobre temáticas na área de Psicologia e nas suas interfaces com as Ciências Humanas e as Ciências da Saúde, problematizando a realidade atual, contribuindo para a prática em Psicologia e promovendo o desenvolvimento teórico. Do ponto de vista metodológico, a revista Psicologia em Estudo publica artigos que se pautem exclusivamente na perspectiva qualitativa. Publica artigos de diferentes abordagens da Psicologia, desde que bem fundamentados teórica e metodologicamente. Os textos são publicados em Inglês e Português. O Qualis é A1.

Palavras-chave: Psicologia. Publicação. Pesquisas qualitativas.

Abstract: The purpose of this poster is to present some information from the journal Psicologia em Estudo. The newspaper has as mission publish original texts on topics in the field of psychology and its interfaces with the Social Sciences and Health Sciences, discussing the current reality, contributing to the practice in psychology and promoting the theoretical development. From the methodological point of view, the journal Psychology Study publishes articles that are driven only in qualitative terms. It publishes articles of different approaches to psychology, if well grounded theoretically and methodologically. The texts are published in English and Portuguese. The Qualis is A1.

Keywords: Psychology. Publication. Qualitative research.

\section{INTRODUÇÃ̃O}

Conforme a abordagem de Figueiredo (1979) podemos afirmar que a estrutura da comunicação cientifica remonta a história da ciência. Nestes termos, cabe mencionar que o surgimento do periódico científico, ainda no século XVII, coincide com o incremento da ciência experimental, tendo em vista que os meios de comunicação utilizados pelos cientistas neste período, a saber, a correspondência particular e a eventual publicação de livros, demonstraram-se inadequados para difusão das novas informações mediante a intensificação da atividade econômica própria desse período que impõe a necessidade de maior fluxo informacional.

Desde então, nas várias ciências temos assistido a criação de novos periódicos, com a intenção de divulgar práticas e pesquisas desenvolvidas. Esta também tem sido a finalidade do periódico Psicologia em Estudo (RPE). Esse periódico científico é uma publicação de caráter institucional, editado e distribuído regularmente desde o segundo semestre de 1996, pelo Departamento de Psicologia e pelo Programa de Pós-Graduação em 
FACCI, M. G. D.; SANCHES, A.;FRANCO, A. F.; ALVES, A. M. P.; FERRAZZA, D. A., BRIDA, G. V. P.; LEITE, H. A.; SOLDERA, L. M.; LIBONE, M. T. L.; MOSCHETA, M.; LEAL, Z. F. R. G.

"“Psicologia em estudo": conhecendo o periódico"

Psicologia, da Universidade Estadual de Maringá (UEM), no Estado do Paraná (PR). A partir de 2008, a periodicidade da revista passou para trimestral. Atualmente o Qualis, avaliação concedida pela CAPES, é A1 e a partir do volume 19, número 4, de 2014, passou a publicar seus artigos nos idiomas português e inglês.

\section{MISSÃO DA REVISTA E POLÍTICA EDITORIAL}

Tem como missão publicar textos originais sobre temáticas na área de Psicologia e nas suas interfaces com as Ciências Humanas e as Ciências da Saúde, problematizando a realidade atual, discutindo temas candentes, que necessitam de um olhar calcado em conhecimentos científicos, contribuindo para a prática em Psicologia e promovendo o desenvolvimento teórico de várias correntes já produzidas historicamente.

Os textos podem ser publicados nas seguintes categorias: relato de pesquisa, revisão de literatura/estudo teórico, relato de experiência profissional, resenha de livro, debate, entrevista, seção especial.

Em casos especiais, podem ser aceitos textos que já tenham sido publicados em periódicos estrangeiros, sujeitos à mesma avaliação de originais inéditos. Entretanto, nesses casos, o autor deverá apresentar autorização, com assinatura do editor da revista em que o texto tenha sido originalmente publicado, anexada de modo online, pelo sistema de editoração da Revista.

Os textos de autores nacionais são aceitos em português. Os textos de autores estrangeiros são aceitos em português, inglês, francês e espanhol, devidamente revisados.

O processo de avaliação por pares utiliza o sistema de blind review, preservando a identidade dos autores e consultores. A decisão final sobre a publicação, ou não, do texto é sempre do Conselho Editorial em conjunto com a Equipe Executiva.

Todo o processo de editoração pode ser acompanhado pelos autores pelo sistema eletrônico, com seu login e senha. O Scientific Journal Ranking (SJR) é 0,144.

\section{CORPO EDITORIAL}

O corpo editorial da revista, a partir de outubro de 2015, é constituído da seguinte forma: 1 editora chefe, 1 editor adjunto, duas editoras assistentes e uma comissão executiva composta de sete participantes. Todos são professores do Departamento de Psicologia, da UEM.

O conselho editorial é composto de 23 professores de universidades brasileiras ou de outros países, com diversidades de campos de atuação e de fundamentação teórica, buscando garantir a qualidade dos pareceres emitidos. 
FACCI, M. G. D.; SANCHES, A.;FRANCO, A. F.; ALVES, A. M. P.; FERRAZZA, D. A., BRIDA, G. V. P.; LEITE, H. A.; SOLDERA, L. M.; LIBONE, M. T. L.; MOSCHETA, M.; LEAL, Z. F. R. G.

"“Psicologia em estudo": conhecendo o periódico"

\section{TEMPO DE PUBLICAÇAO}

O tempo médio entre a submissão, aceitação tem sido em torno de 6 meses. Já o percentual de artigos aceitos com relação ao total recebido é o seguinte:

2014:47\% aprovados e 53\% reprovados

2015: $24 \%$ aprovados e $68 \%$ reprovados

2016: $40 \%$ aprovados e 60\% reprovados

2017 (até a agosto): $47 \%$ aprovados e $63 \%$ reprovados

\section{INDEXADORES}

Os artigos publicados em RPE são indexados ou resumidos por:

- PsycINFO: http://www.apa.org/psycinfo/

- LILACS: http://www.bireme.org

- INDEXPSI: http://www.bvs-psi.org.br

- CLASE: http://dgb.unam.mx/

- EBSCO: http://www.ebsco.com/

- Sociological Abstracts: http://www.csa.com/

- Social Services Abstracts: http://www.csa.com/factsheets/ssa-set-c.php

- Linguistics \& Language Behavior Abstracts:

http://www.csa.com/factsheets/llba-set-c.php

- Scopus: http://info.scopus.com/docs/tittles_list.xls

- Latindex: http://www.latindex.unam.mx

- Ebsco: http://ebscohost.com/academic

- Psicodoc: http://www.psicodoc.org/acerca.htm

- Doaj: http://www.doaj.org

- Redalyc: http://redalyc.uaemex.mx

\section{ALGUMAS CONSIDERAÇOES}

O compromisso assumido pela equipe da RPE é o de sempre melhorar, aprimorando os processos de editoração e a qualidade das publicações, sendo que para isso busca constantemente incrementar ainda mais: 
FACCI, M. G. D.; SANCHES, A.;FRANCO, A. F.; ALVES, A. M. P.; FERRAZZA, D. A., BRIDA, G. V. P.; LEITE, H. A.; SOLDERA, L. M.; LIBONE, M. T. L.; MOSCHETA, M.; LEAL, Z. F. R. G.

"“Psicologia em estudo": conhecendo o periódico"

- As parcerias com profissionais reconhecidos de universidades nacionais e internacionais que compõem nosso Conselho Editorial e que participam das discussões sobre a dinâmica da editoração.

- A inclusão de profissionais com reconhecidos trabalhos e projeção acadêmica que integram o quadro do Conselho Consultivo ad hoc, de universidades de diferentes estados da federação brasileira, bem como internacionais.

É importante destacar que mesmo com as dificuldades enfrentadas na Editoração e publicação em uma Universidade Pública Estadual, do interior do Paraná, que muitas vezes não dispõe de verbas suficientes para sua manutenção, ainda assim vem conseguindo manterse dentro dos requisitos necessários exigidos em nível nacional e internacional.

Outro ponto a considerar é o enfrentamento que a equipe de editores e a comissão executiva do periódico apresenta frente aos problemas vividos nas universidades públicas e com o produtivismo que impera, principalmente na pós-graduação. Tais temáticas tem sido sistematicamente abordadas nos editoriais dos vários números publicados.

O posicionamento da equipe se faz enquanto ato de resistência aos múltiplos ataques às conquistas democráticas; a denúncia aos cortes realizados aos financiamentos de pesquisas; o desmantelamento das universidades públicas; o enfraquecimento dos movimentos reivindicatórios e muitas outras formas de subjugar o homem aos ditames do capital.

Concordamos com as ideias apresentadas por Castiel e Sanz-Valero (2007), que muitas vezes a produção de artigos vira mercadoria, valor de troca no âmbito das academias. As características de mercado, segundo Bernardo (2014), estão presentes nas universidades e o produtivismo acadêmico é filho desta lei do mercado - caracterizado pela competição e produtividade exacerbadas, foco de avaliação do trabalho no professor, principalmente na pós-graduação -, e traz influência na situação de precariedade subjetiva dos docentes, que leva ao desgaste mental, tendo como consequência o sofrimento psíquico e o adoecimento.

Estamos cientes, na editoração da RPE, dessas problemáticas, das contradições que permeiam a sociedade, contudo, ainda continuamos nossa caminhada em frente, buscando trazer ao leitor, por meios dos artigos publicados, formas de compreender a essência dos fatos que ocorrem na realidade, calcado no conhecimento produzido pelas várias ciências, buscando cumprir com uma das funções da universidade que é a socialização dos conhecimentos produzidos pelos homens e também, não poderíamos deixar de mencionar, a luta pela emancipação de todos os homens. 
FACCI, M. G. D.; SANCHES, A.;FRANCO, A. F.; ALVES, A. M. P.; FERRAZZA, D. A., BRIDA, G. V. P.; LEITE, H. A.; SOLDERA, L. M.; LIBONE, M. T. L.; MOSCHETA, M.; LEAL, Z. F. R. G.

"“Psicologia em estudo": conhecendo o periódico"

\section{REFERENCIAS}

BERNARDO, M. H. Produtivismo e precariedade subjetiva na universidade pública: o desgaste mental dos docentes. Psicologia \& Sociedade, Belo Horizonte, v. 26, n. esp., p. 129$139,2014$.

CASTIEL, L. D.; SANZ-VALERO, J. Entre fetichismo e sobrevivência: o artigo científico é uma mercadoria acadêmica? Caderno de Saúde Pública, Rio de Janeiro, v. 23, n. 12, p. 3041-3050, dez. 2007.

FIGUEIREDO, N. O processo de transferência de informação. Ciência da Informação, Rio de Janeiro, v. 8, n. 2, p. 19-138, 1979. 